\title{
VALORES BIOQUÍMICOS SÉRICOS DE TILAPIA DEL NILO (Oreochromis niloticus) EN CULTIVO INTENSIVO
}

\author{
Serum B iochemical Values For Nile Tilapia (Oreochromis niloticus) \\ Cultured Under an Intensive System
}

\author{
Leandro Z. Crivelenti ${ }^{1,2}$, Sofia Borín ${ }^{1}$, José Javier M. Socha ${ }^{1}$, Antonio V. Mundim ${ }^{3}$
}

\section{Resumen}

El objetivo del estudio fue evaluar los parámetros bioquímicos séricos de tilapias del Nilo (Oreochromis niloticus), linaje tailandés chitralada, producidas en un sistema de piscicultura intensiva y capturadas con atarraya. Se tomaron muestras de sangre a 40 ejemplares por punción de la vena caudal. Los peces tenían un peso de $453 \pm 52 \mathrm{~g}$. Se determinó proteína total, albúmina, globulinas, ácido úrico, creatinina, urea, calcio, fósforo inorgánico, relación $\mathrm{Ca} / \mathrm{P}$, magnesio y fosfatasa alcalina. En un contexto general, los resultados mostraron parámetros semejantes a los establecidos para peces de escama, con excepción del ácido úrico.

Palabras clave: tilapia del Nilo, Oreochromis niloticus, bioquímica sérica

\section{Abstract}

The aim of the study was to evaluate the serum biochemical parameters of the Nile tilapia (Oreochromis niloticus), Thai Chitralada lineage, raised under an intensive pisciculture system and captured by the cast net technique. Blood samples from 40 individuals were obtained by caudal venopuncture. Mean body weight was $453 \pm 52 \mathrm{~g}$. The serum biochemical parameters evaluated were total protein, albumin, globulins, acid uric, creatinine, urea, calcium, inorganic phosphorus, $\mathrm{Ca} / \mathrm{P}$ ratio, alkaline phosphatase, and magnesium. In general, the data showed similar parameters in comparison to those established for scale fish, exception of the acid uric.

Key words: Nile tilapia, Oreochromis niloticus, serum biochemistry

\footnotetext{
${ }^{1}$ Universidade Estadual Paulista, campus Jaboticabal, SP, Brazil

${ }^{2}$ E-mail: crivelenti_lz@yahoo.com.br

${ }^{3}$ Universidade Federal de Uberlândia, MG, Brazil
} 
Objetivou-se a avaliação dos parâmetros bioquímicos séricos de tilápias do Nilo (Oreochromis niloticus), linhagem tailandesa Chitralada, produzidas em sistema de piscicultura intensiva e capturadas por tarrafeamento. Amostras sanguíneas de 40 exemplares, pesando em média $453 \pm 52 \mathrm{~g}$, foram obtidas por venopunção caudal e posteriormente analisadas quanto às concentrações séricas de proteína total, albumina, globulinas, ácido úrico, creatinina, ureia, cálcio, fósforo inorgânico, relação $\mathrm{Ca} / \mathrm{P}$, magnésio e fosfatase alcalina. Em um contexto geral, os resultados evidenciaram parâmetros semelhantes aos estabelecidos para peixes de escama, com exceção do ácido úrico.

Palavras-chave: Tilápia do Nilo, Oreochromis niloticus, bioquímica sérica

\section{INTRODUCCIÓN}

La piscicultura brasilera se encuentra en amplia expansión y es considerada una importante fuente de ingresos para pequeños, medianos y grandes productores rurales (Tavares-Dias et al., 2000; Barros et al., 2002). Datos de la Secretaría Especial de Acuicultura y Pesca señalan que los diversos segmentos del sector se han desarrollado en forma acelerada, de tal forma que en el 2000, Brasil produjo cerca de $150000 \mathrm{TM}$ de pescado en cultivo y llegó a estar cerca 250000 TM en el 2002 (SEAP, 2009).

El tipo de producción intensiva y el rápido auge en la actividad productora ha evidenciado problemas relacionados a la crianza, ya que el confinamiento (Barton et al., 2003) y el manejo inadecuado (Tavares-Dias et al., 2000) alteraron el equilibrio fisiológico e incrementaron el riesgo a enfermedades en los peces (Cleary y Pankhurst, 2000).

Tavares-Dias et al. (2000) afirman que evaluaciones precoces en parámetros indicadores de enfermedad pueden garantizar una mejor salud en los peces. En virtud de esto, las variables hematológicas y bioquímicas sanguíneas son herramientas importantes en el diagnóstico de las patologías que afectan a los peces (Carneiro y
Urbinati, 2001; Cnaani et al., 2004). Por ejemplo, los peces son muy sensibles a los cambios ambientales (Siroká y Drastichová, 2004) $\mathrm{y}$ algunas enzimas desempeñan un rol importante en la desintoxicación de contaminantes, de manera que el análisis de estas enzimas proporciona importante información a los investigadores en el monitoreo de los ambientes acuáticos (Cho et al., 1999).

La literatura es abundante en resultados de investigación sobre análisis bioquímicos séricos de diversas especies de peces (Barton et al., 2003; Siroká y Drastichová, 2004), incluyendo la tilapia (Bittencourt et al., 2003; Cnaani et al., 2004); sin embargo, la literatura científica en América del Sur es aún escasa para especies cultivadas o nativas.

La edad, sistema de cría (Bittencourt et al., 2003), sexo (Svobodová et al., 1998) y métodos de contención son factores que afectan los valores bioquímicos en sangre de peces y por lo tanto deben ser tomados en cuenta cuando se busca caracterizar los perfiles bioquímicos (Sandnes et al., 1988; Lusková, 1997). El presente estudio tuvo como objetivo evaluar los parámetros bioquímicos séricos de la tilapia del Nilo (Oreochromis niloticus) tailandesa chitralada, producidas en sistema de piscicultura intensiva y capturadas con atarraya. 


\section{Materiales y Métodos}

Se trabajó con 40 tilapias (O. niloticus v. chitralada) unisexuales machos, colectadas en Lagoa da Prata, municipio de Batatais - SP, Brasil. El sitio emplea un sistema de cría intensiva con densidad poblacional de aproximadamente 4 peces $/ \mathrm{m}^{2}$, en tanques de tierra, con agua corriente y $3200 \mathrm{~m}^{2}$ de lámina de agua.

La alimentación se realiza tres veces al día con ración comercial de crecimiento y engorde (28\% de proteína bruta [PB], $6 \%$ de extracto etéreo, $3 \%$ de calcio [máx.] y $0.5 \%$ de fósforo [mín.]). Las tilapias se comercializan en el club de pesca y en el mercado local cuando alcanzan $0.5 \mathrm{~kg}$ de peso.

Se evaluaron los parámetros físicos y químicos del agua en los tres días anteriores al experimento y diez minutos antes de la captura. La temperatura fue verificada por medio de lectura directa y los demás parámetros por métodos colorimétricos (kit Red Sea $\left.{ }^{\circledR}\right)$. Las tilapias fueron sometidas a 12 horas de ayuno previo a la captura con atarraya ( $2.5 \mathrm{~m}$ de radio y malla de nylon de $3 \mathrm{~cm}$ de diámetro).

Los peces se colocaron en una caja plástica con perforaciones laterales y se llevaron hasta un tanque de agua corriente y abundante, donde permanecieron por unos minutos hasta la toma de la muestra sanguínea. Se emplearon toallas humedecidas para la inmovilización y vendaje de los ojos. Cada animal fue sometido a una punción venosa caudal para obtener $5 \mathrm{ml}$ de sangre. Luego, los peces fueron sacrificados conforme a la rutina del lugar y las vísceras fueron inspeccionadas macroscópicamente.

Las muestras de sangre se colectaron en tubos sin antic oagula nte y fueron centri- fugadas a $720 \mathrm{G}$ por 10 minutos para la obtención de suero. Este fue transferido en alícuotas de $2 \mathrm{~mL}$ en micro tubos y congelados a $-20{ }^{\circ} \mathrm{C}$. Las muestras fueron trabajadas en el Laboratorio de Análisis de la Clínica del Hospital Veterinario de la Facultad de Medicina Veterinaria de la Universidade Federal de Uberlândia (UFU).

Se determinó la concentración de proteína total (método biuret), albúmina (verde de bromocresol), globulinas (calculadas por la diferencia entre proteínas totales y la albúmina), relación albúmina/globulina, ácido úrico (método enzimático Trinder), creatinina (método del picrato alcalino), urea (método ureasa colorimétrico), calcio (método de la cresolftaleína complexona), fósforo inorgánico (método del fosfomolibdato), relación $\mathrm{Ca} /$ P, magnesio (método Magón sulfonado) y la actividad de la enzima fosfatasa alcalina (método Roy modificado) utilizando el sistema Labtest ${ }^{4}$ para diagnóstico. Las lecturas fueron realizadas en espectrofotómetro ${ }^{5}$ semiautomático.

La información se analizó mediante estadística descriptiva, considerando el promedio, desviación estándar, valor mínimo, valor máximo y coeficiente de variación, por el programa Graph Prism 4.

\section{Resultados y Discusión}

La cría de tilapias en el sitio Lagoa da Prata emplea un sistema de manejo intensivo similar a la mayoría de las piscigranjas brasileras. La densidad poblacional de los peces en el tanque de terminación fue aceptable, toda vez que Silva et al. (2000) indican la posibilidad de utilizar hasta 4 peces $/ \mathrm{m}^{2} \sin$ ocasionar perjuicio al desempeño productivo de la tilapia. Se optó por pesca con atarraya por su bajo costo y menor tiempo para la captura; asimismo, este método es empleado

\footnotetext{
${ }^{4}$ LABTEST - Labtest Diagnóstica, Lagoa Santa, Brasil

${ }^{5}$ LABQUEST-LABTEST - Labtest Diagnóstica, Lagoa Santa, Brasil
} 
Cuadro 1. Valores promedio y desviación estándar, máximo y mínimo, y coeficiente de varianza de los parámetros bioquímicos séricos de tilapias del Nilo $(O$. niloticus) $\mathrm{n}=40$ criadas en tanque, en sistema intensivo

\begin{tabular}{lcccc}
\hline Parámetros & Promedio \pm de & Máximo & Mínimo & $\begin{array}{c}\text { Coeficiente de } \\
\text { varianza }(\%)\end{array}$ \\
\hline Proteínas totales $(\mathrm{g} / \mathrm{dL})$ & $3.01 \pm 0.45$ & 2.18 & 4.49 & 15.04 \\
Albúmina (g/dL) & $0.86 \pm 0.15$ & 0.67 & 1.27 & 16.86 \\
Globulinas $(\mathrm{g} / \mathrm{dL})$ & $2.15 \pm 0.41$ & 1.18 & 3.55 & 19.36 \\
Creatinina $(\mathrm{mg} / \mathrm{dL})$ & $0.54 \pm 0.18$ & 0.16 & 0.97 & 34.32 \\
Urea $(\mathrm{mg} / \mathrm{dL})$ & $8.19 \pm 2.08$ & 2.25 & 13.38 & 25.44 \\
Ácido úrico $(\mathrm{mg} / \mathrm{dL})^{*}$ & $3.2 \pm 5.21^{*}$ & 0.00 & 24.74 & $162.61^{*}$ \\
Calcio $(\mathrm{mg} / \mathrm{dL})$ & $11.43 \pm 1.08$ & 9.00 & 14.26 & 9.47 \\
Fósforo $(\mathrm{mg} / \mathrm{dL})$ & $9.31 \pm 2.70$ & 3.93 & 15.57 & 29.07 \\
Relación Ca:P & $1.35 \pm 0.43$ & 0.81 & 2.69 & 31.79 \\
Magnesio (mg/dL) & $3.28 \pm 0.71$ & 1.77 & 4.26 & 21.85 \\
Fosfatasa alcalina (U/L) & $15.91 \pm 4.29$ & 8.49 & 31.84 & 27.00 \\
\hline
\end{tabular}

* Datos no paramétricos

cotidianamente por los profesionales del área y no requiere el uso de tanques de contención química.

Los parámetros de calidad de agua fueron de $25.4 \pm 0.3{ }^{\circ} \mathrm{C}$, pH: $6.9 \pm 0.2$, alcalinidad total: $35 \mathrm{mg} / \mathrm{L}$, amonio total: $>0.5 \mathrm{ppm}$ y nitrito y nitrato: $0 \mathrm{ppm}$, valores dentro de lo recomendado por Tavares-Dias et al. (2000) para la especie.

El peso de las tilapias fue de $453 \pm 52 \mathrm{~g}$ a los 6 meses de edad. No se observaron lesiones o alteraciones macroscópicas significativas externas o internas, ocasionadas en la captura o por la venopunción. Los valores bioquímicos séricos obtenidos son presentados en el Cuadro 1.

Con excepción del ácido úrico, los demás parámetros presentaron resultados dentro de la curva de normalidad, lo cual es indi- cativo que estos valores pueden ser utilizados como valores referenciales en la evaluación de tilapias criadas en sistemas intensivos.

Cnaani et al. (2004) reportaron menores niveles de urea sérica en peces con pesos inferiores, lo que podría deberse a una mayor ingestión proteica asociada a una mayor actividad metabólica en tilapias de mayor peso; sin embargo, esto no pudo establecerse en este estudio al haber utilizado peces con peso uniforme. Por otro lado, debe tenerse en cuenta que los valores de creatinina son más fidedignos que los niveles de urea, dado que presentan menor variación individual, e independientemente del peso y la alimentación.

La concentración de albumina tiene mayor importancia clínica que la proteína total; sin embargo, muy pocos trabajos relacio- 
nados a peces utilizan este análisis y mayormente se refieren a la proteína total. La concentración de proteína total puede ser una herramienta útil, tanto como evidencia de una nutrición ineficiente evidenciado a través de una diminución de la albumina sérica, como una señal de infecciones sistémicas, al haber un aumento de las globulinas circulantes (Bush, 2004). Sin embargo, el empleo de este parámetro sérico debe realizarse entre peces de mismos hábitos alimentarios, sexo y periodo reproductivo debido a variaciones fisiológicas entre especies (Svoboda et al., 2001). Los valores de proteína total del presente estudio fueron similares a otros reportes (3.06 g/dL, Bittencourt et al., 2003; $3.6 \mathrm{~g} /$ dL, Cnaani et al., 2004) en tilapias $O$. niloticus. Por otro lado, se dispone de observaciones de aumento de la proteína total plasmática en el periodo pre-desove de Silurus glanis L. de vida libre (Svobodová et al., 1998) y en peces adultos de Salmo trutta, Thymallus thymallus y Chondrostoma nasus en el periodo de desove (Lusková, 1997); sin embargo, estas alteraciones no son comparables con los resultados del presente estudio, ya que se trabajó con machos mantenidos en confinamiento.

Calcio, fósforo y magnesio son parámetros poco abordados en la mayoría de los trabajos de investigación, pese a que sus valores pueden estar afectados por la alimentación (Cnaani et al. 2004). Mayores estudios en el uso de minerales en la dieta podrían mejorar la calidad de la ración utilizada en esos sistemas de cría.

La fosfatasa alcalina (ALP) es una enzima secretada principalmente por las células de los ductos biliares, hepatocitos y células óseas. Valores de ALP superiores a los de este trabajo fueron encontrados por Cnaani et al. (2004) $(38.5 \pm 9.7 \mathrm{U} / \mathrm{L})$ en tilapias más jóvenes, lo que puede ser explicado por una mayor actividad de isoenzimas óseas, ya que el aumento de la actividad de la ALP puede ocurrir por colestasis hepática, aumento en la producción de isoenzimas en el hipercortisolemia, septicemia/endotoxemia y en el crecimiento acelerado (Bush, 2004).
La mayoría de los parámetros permanecieron próximos al intervalo establecido para peces de escama (Svoboda et al., 2001; Bittencourt et al., 2003; Cnaani et al., 2004), por lo que se destaca la importancia de la estandarización de los métodos de captura, la descripción de los aspectos demográficos, y la calidad del agua y de la dieta, a fin de posibilitar comparaciones entre diversos tipos de producción. Los resultados obtenidos pueden ser usados para monitorear de la sanidad de tilapias del Nilo Oreochromis niloticus variedad Chitralada cultivadas en sistema de cría intensiva.

\section{Agradecimientos}

A la médico veterinaria Mariana Cristina Hoeppner Rondelli por la versión del resumen en idioma inglés.

\section{Literatura Citada}

1. Barros MM, Pezzato LE, Kleemann GK, Hisano H, Rosa GJD. 2002. Levels of vitamin $\mathrm{C}$ and iron for nile tilapia (Oreochromis niloticus). Rev Bras Zootec 31: 2149-2156.

2. Barton BA, Haukenes AH, Parsons BG, Reed JR. 2003. Plasma cortisol and chloride stress responses in juvenile Walleyes during capture, transport, and stocking procedures. N Am J Aquacult 65: 210-219.

3. Bittencourt NLR, Molinari LM, Scoaris DO, Pedroso RB, Nakamura CV, Ueda-Nakamura T, Dias Filho BP. 2003. Haematological and biochemical values for Nile tilapia Oreochromis niloticus cultured in semiintensive system. Acta Scient 25: 385389.

4. Bush BM. 2004. Interpretação de resultados laboratoriais para clínicos de pequenos animais. São Paulo: Roca. $\mathrm{p}$ 238-239.

5. Cnaani A, Tinman S, Avidar Y, Ron M, Hulata G. 2004. Comparative study of biochemical parameters in response 
to stress in Oreochromis aureus, $O$. mossambicus and two strains of $O$. niloticus. Aquac Res, Amsterdam 35: 1434-1440.

6. Carneiro PCF, Urbinati EC. 2001. Plasma electrolyte disturbance in matrinxã, Brycon cephalus, transported under influence of benzocaine. J Appl Aquaculture 11(4): 1-13.

7. Cleary JJ, Pankhurst NW. 2000.The effect of capture and handling stress on plasma steroid levels and gonadal condition in wild and farmed snapper Pagrus auratus (Sparidae). J Word Aquacult Soc 31: 558-569.

8. Cho JR, Kim YJ, Hong KJ, Yoo JK, Lee JO, Ahn YJ. 1999. Resistance monitoring and enzyme activity in fieldcollected populations of the spiraea aphid, Aphis citricola Van der Goot. J AsiaPac Entomol 2: 113-119.

9. Lusková V. 1997. Annual cycles and normal values of hematological parameters in fishes. Acta Sci Nat Brno 31: 1-70.

10. Sandnes K, Lie O, Waagbo R. 1988. Normal ranges of some blood chemistry parameters in adult farmed Atlantic salmon, Salmo salar. J Fish Biol 32: 129-136.

11. [SEAP] Secretaria Especial de Aquicultura e Pesca. 2009. [Internet] [11 mayo 2009]. Disponible en: http:// tuna.seap.gov.br/seap/html/aquicultura/ index.htm

12. Silva PC, Souza VL, Pádua DMC, Dalacorte PC. 2000. Effect of stocking density on the growth of the tetra hybrid red tilapia (Israeli strain). In: Proc Fifth International Symposium on Tilapia Aquaculture. Rio de Janeiro. 2: 341-345.

13. Siroká Z, Drastichová J. 2004. Biochemical markers of aquatic environment contamination - cytochrome P450 in fish - a review. Acta Vet Brno 73: 123-132.

14. Svoboda M, Kouril J, Hamackova J, Kalab P, Savina L, Svobodova Z, Vykusova, B. 2001. Biochemical pro file of blood plasma of tench (Tinca tinca L.) during pre- and postspawning period. Acta Vet Brno 70: 259-268.

15. Svobodová Z, Kolá Äová J, Modrá H, Vajcová V, Hamá ̇̀ová J, Koü̈l J, Kozák P. 1998. Values of hematological indices of wels (Silurus glanis L.) in relationship to the level of nutrition during the pre-spawning period. Acta Vet Brno 67: 235-242.

16. Tavares-Dias M, Schalch SHC, Martins ML. 2000. Características hematológicas de Oreochromis niloticus (Osteichthyes: Cichlidae) cultivada intensamente em pesque-pague do município de Franca, SP, Brasil. Ars Veterinária 16: 76-82. 